\title{
Ovarian Pregnancy - A Rare Case Report
}

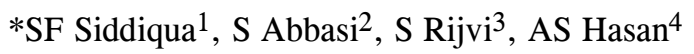

\begin{abstract}
Ovarian pregnancy is a rare form of the non-tubal ectopic pregnancy. Primary ovarian ectopic pregnancy means implantation of the gestational sac in the ovary. Its incidence after natural conception ranges from 1 in 2000 to 1 in 60000 deliveries and accounts for 3\% of all ectopic pregnancies. It ends with rupture before the end of the first trimester. The preoperative diagnosis of this type of pregnancy is not easy. It is characterized by a poor clinical symptomatology and a difficult ultrasound diagnosis but confirmed by histological findings. For the management, Conservative laparoscopic surgery involves ovarian resection or aspiration of the pregnancy with coagulation of the implantation site. However, in case with profuse intraperitoneal bleeding an oophorectomy or salpingo-oophorectomy may be necessary to achieve hemostasis. We report here one such uncommon case of ovarian ectopic pregnancy. Our patient is a 27 years old nulliparous woman came with severe hypogastric pain. During laparoscopy, ruptured ovarian ectopic pregnancy was diagnosed, and wedge resection of the ovary was only done. Histopathological examination confirmed it to be an ovarian ectopic pregnancy.
\end{abstract}

Key Words: Ectopic Pregnancy, Ovarian Pregnancy, Laparoscopy.

\section{Introduction}

An ectopic pregnancy is characterized by implantation and development of an embryo outside of the uterine cavity ${ }^{1}$. Ectopic pregnancies can occur in the ovary $(3.2 \%)$. The surgical criteria remain hard to prove. In true ovarian pregnancy, the ovum is fertilized while it is in the graffian follicles or in the processes of leaving the follicles. The pregnancy then develops within a capsule of ovarian tissues with the corpus luteum immediately alongside it. ${ }^{1}$

Endometriosis on the surface of an ovum is said to favor implantation of a fertilized ovum in the peritoneal cavity. The criteria for a diagnosis of ovarian pregnancy are the tube and its fimbriae are normal and separate from the pregnancy sac, the pregnancy sac is in the position of the ovary, the pregnancy sac is attached to the uterus by the ovarian ligament, ovarian tissue is histologically distinguishable in the several means of the wall around the pregnancy. These criteria are generally attributed to ovarian pregnancy. ${ }^{2}$ The ovary can only accommodate the pregnancy for a short period within 2-3 weeks, the capsule bursts or is eroded and is the source of intra-abdominal hemorrhage.

\section{Case Report}

A 27 years old lady came with the complains of amenorrhea for 7 weeks and irregular per vaginal bleeding for 10 days which was scanty in amount. She had severe lower abdominal pain for 1 day and had history of syncopal attack. She was regularly menstruating. She is married for one year. On examination, she had pallor, a pulse of $105 / \mathrm{min}$, and blood pressure of $95 / 50 \mathrm{~mm} \mathrm{Hg}$. The left

$1 *$ Prof. Sehereen Farhad Siddiqua, Head, Dept. of Obstetrics and Gynecology Anwer Khan Modern Medical College hospital

${ }^{2}$ Dr. Sharmin Abbasi, Assistant Professor, Dept. of Obstetrics and Gynecology Anwer Khan Modern Medical College hospital

${ }^{3}$ Dr. Shifin Rijvi, Register, Dept. of Obstetrics and Gynecology Anwer Khan Modern Medical College hospital

${ }^{4}$ Dr. Abrar Saqif Hasan, Resident Student, Cardiology, Ibrahim Cardiac Hospital And Research Institute

*Corresponding Author

Date of submission: 24. 05.2019 Date of acceptance: 20.06.2019

AKMMC J 2019; 10(2) : 183-185 
adnexal region was not palpable, whereas there was tenderness in the right iliac fossa. Vaginal examination showed normal uterine size and no cervical motion tenderness, whereas pain at deep palpation of the right fornix was revealed.

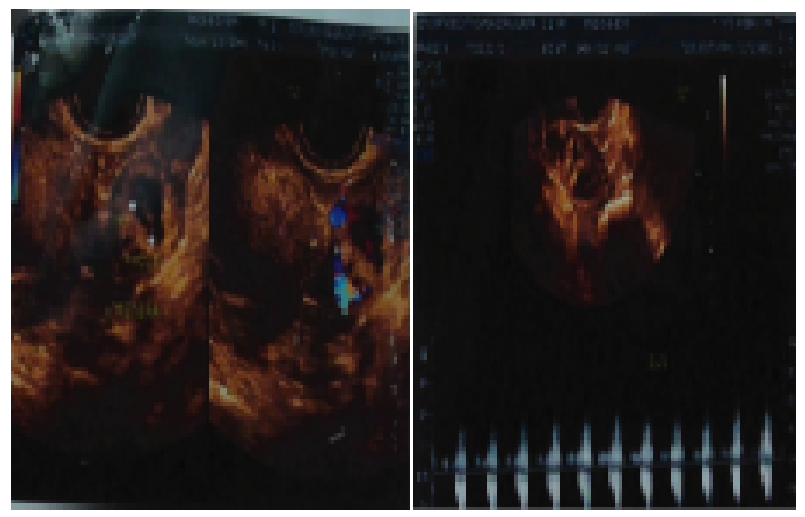

Figure 1:6 weeks 2 days pregnancy with cardiac pulsation in left adnexal region.

TVS report showed uterus was bulky. No gestational sac within the uterus. Both the ovaries appeared normal. Thick walled anechoic area with gestational sac was seen in left adnexal region. CRL-5. $6 \mathrm{~mm}$ corresponding with 6 weeks 02 days is seen with cardiac pulsation is present. Mild collection of fluid is seen in left adnexal region. Her $\beta$ HCG level was $24,362 \mathrm{mIu} / \mathrm{ml}$. Considering patient's symptoms, signs and investigations reports it was suspected rupture ectopic pregnancy and decision was taken for laparoscopy.

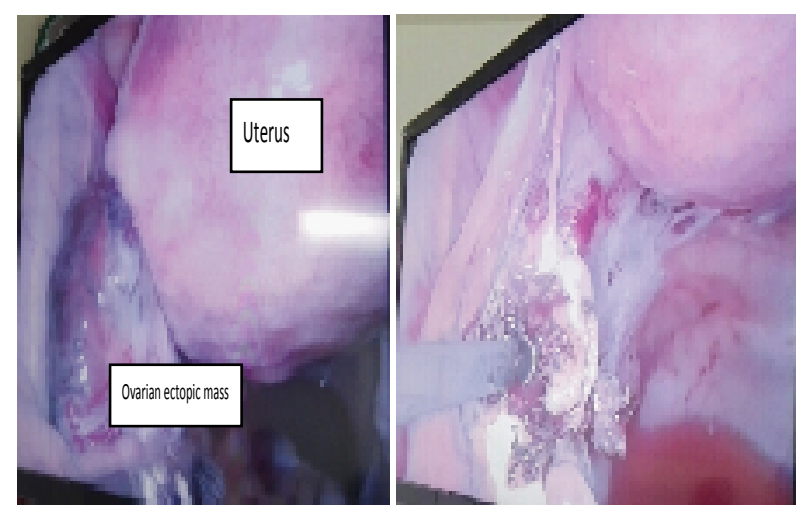

Figure 2: Laparoscopic image showed ovarian pregnancy

Laparoscopic exploration revealed a normal uterus with both fallopian tubes regular. The left ovary was normal, while the right ovary was enlarged with oozing of blood from the surface of an orange-red mass. Blood in the pouch of Douglas was observed. Resection of ectopic mass was done. Hemostasis was appropriate. The postoperative period was uneventful, and the patient was discharged $2 \mathrm{~d}$ after the operation. On histopathological examination, a villous structure embedded in the ovarian tissue were seen, which was confirmatory of primary ovarian pregnancy.

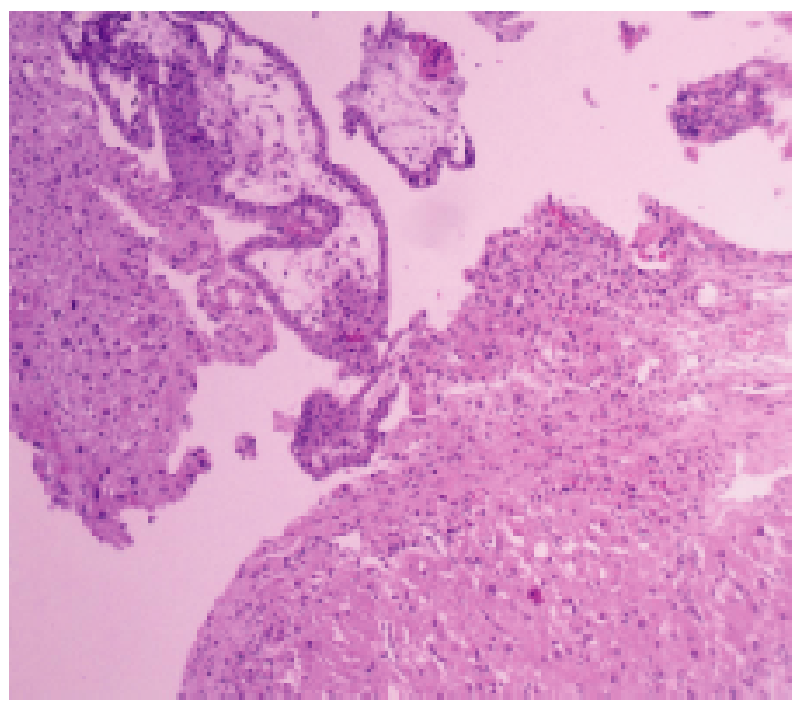

Figure 3: Histopathological photomicrographs showing ovarian tissue decidual tissue with chorionic villi.

\section{Disscussion}

Approximately $74 \%$ of woman with ovarian pregnancy are unaware. ${ }^{2}$ Incidence is likely to be under estimated as many conceptuses die and involute spontaneously. Moreover, some of the suspected tubal pregnancies are treated conservatively with methotrexate without laparoscopic validation. ${ }^{3}$

Our patient denied any risk factors for ovarian pregnancy such as ART, PID, IUCD. It can be hypothesized that this primary ovarian pregnancy resulted from intrafollicular fertilization that took place following failure of ovum extrusion after follicular rupture. ${ }^{4}$

For our patient medical treatment was not tried as the patient's condition and investigation reports demanded immediate surgery, However etoposide 
and methotrexate use was contemplated after surgery if beta hCG levels reminded elevated, indicative of persistent trophoblastic tissue. ${ }^{5}$ The differential diagnosis for ovarian pregnancy, both sonographically and at the time of surgery, remains a clinical challenge- that is to distinguish ovarian pregnancy from a corpus luteal cyst or hemorrhagic cyst $^{6}$ or even ruptured chocolate cyst.

The outcome following a primary ovarian pregnancy as, unlikely tubal pregnancy and secondary ovarian pregnancy, fertility is preserved and recurrence is a rarerity. 7

\section{Conclusion}

Despite modern diagnostic modalities, most of the patients continue to present to us with circulatory collapse due to rupture of ectopic mass. The necessity to maintain a high index of suspicion is required to ensure an efficient mode of treatment, appropriate prognosis. Even though ovarian ectopic pregnancy is commonly managed surgically, still no problem is noticed in case of subsequent future pregnancy.

\section{Conflict of interest: None.}

\section{References}

1. JEFFCOATES, PRINCIPLES OF GYNAECOLOGY, Seventh edition, page: 155

2. Spiegelberg O: Zur Casuitik der Ovarialschwangerschaft. Arch Gynekol.1873; 13: 73 -79

3. Raziel A, Schachter M, Mordechai E, et al. Ovarian pregnancy - a 12 year experience of 19 cases in one institution. Eur J Obstet Gynecol Reprod Biol. 2004 May 10; 114(1): 92-6

4. Comstock C, Huston K, Lee W. The ultrasonographic appearance of ovarian ectopic pregnancies. Obstet Gynecol. 2005; 105: 42-45

5. Juan YC, Wang PH, Chen CH, et al. Successful treatment of ovarian pregnancy with laparoscopy - assisted local injection of etoposide. Fertil steril.2008; 90:1200. E1-2

6. Stein MW, Ricci ZJ, Novak L, et al. Sonographic camparison of the tubal ring of ectopic pregnancy with the corpus luteum. J Ultrasound Med. 2004; 23: 57-62.

7. Gray CL, Ruffolo EH. Ovarian pregnancy associated with intrauterine contraceptive devices. Obstet Gynecol 1978; 10: 132-134. 